\title{
Metastatic clear cell carcinoma of the kidney: therapeutic role of bevacizumab
}

This article was published in the following Dove Press journal:

Cancer Management and Research

25 March 2010

Number of times this article has been viewed

\section{Ronald M Bukowski \\ Cleveland Clinic Taussig Cancer Center, CCF Lerner College of Medicine of CWRU Cleveland, $\mathrm{OH}$, USA}

Correspondence: Ronald M Bukowski Professor of Medicine, Cleveland Clinic Taussig Cancer Center, 28099 Gates Mills Blvd, Pepper Pike, Cleveland, $\mathrm{OH} 44 \mathrm{I} 24$, USA

Tel +| 216-464-573|

Email bukow464@sbcglobal.net

\begin{abstract}
The biology and pathogenesis of clear cell carcinoma of the kidney has been extensively investgated, and the role of von Hipple-Landau gene inactivation and tumor associated angiogenesis is now recognized. Development of vascular endothelial growth factor inhibitors and phase 3 clinical trials utilizing this class of agents has produced a new treatment paradigm for patients with metastatic renal cell carcinoma (RCC). One of the active regimens identified is the combination of bevacizumab and interferon- $\alpha$. Recently published reports provided evidence of the clinical and biologic activity of this therapy. The current manuscript reviews the background and rationale for the activity of bevacizumab in RCC, and results from recent clinical trials with this agent alone or in combination with targeted agents or cytokines. The role of this therapy in contrast to other targeted agents is reviewed, and the potential utility as well as questions raised by recent studies are discussed.
\end{abstract}

Keywords: metastatic renal cell carcinoma, bevacizumab, interferon- $\alpha$

\section{Introduction}

Renal cell carcinoma (RCC) accounts for $2 \%$ to $3 \%$ of all solid tumors in adults, and over 50,000 new cases were diagnosed in the United States in 2009. ${ }^{1}$ The primary treatment of localized RCC involves surgical resection or local nonsurgical ablative techniques. Systemic therapy is utilized when advanced or metastatic disease is present. Recently a new paradigm has been developed for systemic therapy of RCC that targets specific pathways in this neoplasm. The role of von Hippel-Lindau (VHL) gene inactivation in clear cell $\mathrm{RCC}^{2}$ provided an explanation for the long recognized angiogenic features of kidney cancer, and was followed by the development of vascular endothelial growth factor (VEGF) pathway inhibitors as a new standard of care for patients with metastatic disease. Based on these studies, a new treatment approach then developed utilizing drugs targeting components of this pathway. Sunitinib ${ }^{3}$ and temsirolimus ${ }^{4}$ are considered frontline agents for the management of renal cell carcinoma. Recently, reports by Escudier et $\mathrm{al}^{5}$ and Rini et $\mathrm{al}^{6}$ have provided evidence the combination of bevacizumab and interferon- $\alpha$ (IFN- $\alpha$ ) is also an effective strategy for initial therapy of metastatic RCC. This review summarizes the rationale, clinical data, and the results from contemporary studies, as well as exploring the future role of bevacizumab in RCC therapy.

\section{Clear cell carcinoma biology}

A growing understanding of the molecular biology of RCC has identified a number of pathways pertinent to the development and progression of clear cell RCC. 
Activation of the hypoxia response pathway by mutations of the von Hippel-Lindau ( $V H L$ ) tumor suppressor gene produces transcriptional activation of genes important in tumor progression, including vascular endothelial growth factor (VEGF), a potent promoter of tumor-associated angiogenesis. ${ }^{2,7}$ The $V H L$ gene encodes a 213 amino acid protein ( $\mathrm{pVHL}$ ) which functionally regulates the normal cellular response to oxygen deprivation. In conditions of physiologic oxygen availability and normal $V H L$ gene function, pVHL is a component of an ubiquitin ligase complex that targets a family of protein transcription factors, the hypoxia-inducible factors (HIF $1 \alpha$ and HIF $2 \alpha$ ) for proteolysis. Under hypoxic conditions, this interaction is disrupted secondary to loss of oxygen-dependent hydroxylation of HIF, leading to stabilization of the HIF transcription factors. ${ }^{8}$ In the presence of a defective $V H L$ gene and/or loss of protein function, the interaction between $\mathrm{pVHL}$ and HIF is disrupted despite the presence of adequate oxygen. HIF is not degraded, is constitutively activated, translocates to the nucleus, and promotes transcription of various hypoxiainducible genes. ${ }^{9}$ Several of these are critical mediators of tumorigenesis, such as VEGF. ${ }^{9}$

In sporadic (non-inherited) RCC, VHL gene allele deletion (loss of heterozygosity) has been demonstrated in $84 \%$ to $98 \%$ of sporadic renal tumors, and examination of RCC tumors for mutation in the remaining $V H L$ allele has been observed in $34 \%$ to over $80 \%$ of clear cell RCC tumors. ${ }^{10,11}$ VHL gene inactivation in RCC may also occur through gene silencing by methylation. ${ }^{12}$ Taken together, the above data suggest that VEGF inhibitors should be a focus of drug development in this neoplasm.

\section{Vascular endothelial growth factor (VEGF)}

In 1948, Michaelson identified a soluble "angiogenic factor X" which promoted the growth of retinal vessels. ${ }^{13}$ This factor was eventually identified as VEGF. It was also referred to as VPF (vascular permeability factor) and functions as an important regulator of endothelial cell biology. VEGF was identified in 1989 as a secreted mitogen of endothelial growth, ${ }^{14}$ and is now recognized as a dominant factor in tumor growth and development. VEGF regulates vascular endothelial cells, promoting both proliferation and new vessel formation. This ligand-mediated response occurs during normal physiological angiogenesis, such as wound healing and uterine decidua formation, as well as in pathologic situations such as cancer. Tumor-associated angiogenesis is dependent on secreted VEGF to promote existing vessel ingrowth into the tumor as well as neovascularization.
Because of the importance of VEGF in this process, it has a critical role in tumor associated angiogenesis.

VEGF defines a family of related peptides, each with restricted tissue expression and receptor specificity. VEGF-A is structurally related to the platelet-derived growth factor (PDGF) family, sharing homology with both PDGF-A and PDGF-B. Originally, VEGF-A was identified as a $45 \mathrm{kD}$ protein produced by pituitary cells. ${ }^{15}$ The active portion of the protein identified was the 26 amino acid signal sequence at the $\mathrm{N}$ terminus of the molecule. The VEGF-A gene is located at 6 221.3. ${ }^{16}$ Human VEGF-A has at least 9 subtypes due to the alternative splicing of a single gene. ${ }^{17,18}$

The various activities of the VEGF isoforms is an area of active investigation. Selected isoforms such as VEGF-165b can act in a dominant negative fashion. This isoform binds to VEGF-R2 with the same affinity as VEGF165, but does not activate downstream signaling pathways. ${ }^{17}$ Mice engineered to express only VEGF121, die within the first 2 weeks of life secondary to ischemic cardiomyopathy and failure of myocardial angiogenesis. ${ }^{19,20}$ In mice lacking VEGF165, severe defects in developing blood vessels are seen.

VEGF is primarily produced and secreted by fibroblasts. ${ }^{21}$ Its expression is regulated by a series factors including growth factors, p53 mutation, estrogen receptor activation, thyroid stimulating hormone, nitric oxide, and hypoxia. Inappropriate activation of the hypoxia response pathway, is the major mechanism of VEGF transcriptional regulation in renal cell carcinoma. ${ }^{2}$ The HIF $\alpha$ subunits activated by either inactivation of VHL or hypoxia heterodimerize with a constitutively available HIF1 $\beta$ (aryl hydrocarbon receptor nuclear transferase, ARNT). This complex can then bind a hypoxia response element, and induce VEGF transcription. ${ }^{22}$

\section{VEGF function}

Secreted VEGF is a mitogen for capillary and vascular endothelial cells. ${ }^{15,23}$ It stimulates proliferation of endothelial cells, through binding and dimerization of cell surface receptors. FLT1 (VEGFR1) and KDR/FLK1 (VEGFR2) are the major receptors which bind VEGFA. They are only found on endothelial cells, and it appears VEGF isoforms compete for receptor binding. Specifically, VEGF145, the major tumorassociated isoform, will inhibit the binding of VEGF165 to the KDR/FLK1 receptor. ${ }^{24}$ Additionally, VEGF regulates the permeability of blood vessels,${ }^{25}$ in a dose dependent manner. Increased vessel permeability is a critical step for the abnormal transport of molecules and cells across the blood vessel wall and, therefore, may be a crucial abnormality in tumor growth and metastasis. ${ }^{26}$ 


\section{Bevacizumab: VEGF monoclonal antibody}

Bevacizumab (rhuMAb VEGF, Avastin ${ }^{\circledR}$; Genentech, South San Francisco, CA) is a recombinant human monoclonal antibody that binds and neutralizes all biologically active isoforms of VEGF. ${ }^{27}$ In vitro studies have demonstrated bevacizumab decreases both the survival of human vascular endothelial cells (HUVEC) and VEGF-induced HUVEC permeability. ${ }^{28}$ It inhibits proliferation of bovine capillary endothelial cells in response to VEGF, and has anti-tumor effects against selected sarcoma and breast cancer cell lines. ${ }^{27}$ Additionally, bevacizumab has activity against metastases in a variety of preclinical models. ${ }^{29}$ Finally, Rowe et al ${ }^{30}$ reported the antibody (A4.6.1) prevented lung metastases from Wilm's tumors implanted into kidneys of nude mice. A series of clinical trials were then performed which defined the toxicity and efficacy of bevacizumab.

\section{Bevacizumab: clinical trials Phase I trials}

The initial clinical evaluation of bevacizumab involved a series of phase 1 trials in patients with refractory solid tumors. Gordon et $\mathrm{al}^{31}$ reported a phase 1 trial of bevacizumab in patients with metastatic cancer who had failed prior therapy. It was administered as a 90-minute intravenous (IV) infusion at doses from 0.1 to $10.0 \mathrm{mg} / \mathrm{kg}$ on days $0,28,35$, and 42 . Twenty-five patients including 7 with metastatic RCC were accrued. There were no grade III or IV adverse events related to the antibody, and 3 episodes of tumor-related bleeding were noted. Bevacizumab Infusions were well tolerated without significant toxicity. Grades I and II adverse events probably related to bevacizumab included asthenia,headache, and nausea. Pharmacokinetic studies revealed a half-life of 21 days. There were no objective responses; however, 6/7 RCC patients experienced stable disease over the duration of the study. This included 1 patient with metastatic RCC in whom a minor response characterized as $<30 \%$ reduction of pulmonary and lymph node lesions was seen. Bevacizumab was safely administered without dose-limiting toxicity at doses ranging up to $10 \mathrm{mg} / \mathrm{kg}$, and multiple doses were well tolerated. The pharmacokinetic studies indicated that doses of $>0.3 \mathrm{mg} / \mathrm{kg}$ had a half-life similar to that of other humanized antibodies. This initial trial demonstrated a favorable acute toxicity profile, and in retrospect suggested activity in RCC.

A second phase 1 trial investigated the safety and pharmacokinetics of weekly intravenous bevacizumab combined with one of three standard chemotherapy regimens. ${ }^{32}$ Twelve patients were treated (4 receiving each combination) with bevacizumab $3 \mathrm{mg} / \mathrm{kg}$ IV weekly for 8 weeks with either (1) doxorubicin $50 \mathrm{mg} / \mathrm{m}^{2}$ every 4 weeks; (2) carboplatin at area under the curve of 6 plus paclitaxel $175 \mathrm{mg} / \mathrm{m}^{2}$ every 4 weeks; or (3) fluorouracil $500 \mathrm{mg} / \mathrm{m}^{2}$ with leucovorin $20 \mathrm{mg} / \mathrm{m}^{2}$ weekly, weeks 1 to 6 every 8 weeks. Grade 3 toxicities attributed to chemotherapy included diarrhea (1 patient), thrombocytopenia (2 patients), and leukopenia (1 patient). The mean $( \pm \mathrm{SD})$ peak serum level of bevacizumab was $167 \pm$ $46 \mu \mathrm{g} / \mathrm{mL}$, and mean terminal half-life 13 days. One patient with refractory RCC received doxorubicin and bevacizumab, and had a partial response. The patient received 36 doses of antibody with no cumulative or late toxicities noted. This study not only demonstrated the safety of bevacizumab combined with chemotherapy, but also again suggested possible activity in patients with metastatic RCC.

\section{Phase 2 trials}

A series of phase 2 trials were then conducted in patients with metastatic RCC, and demonstrated the therapeutic activity of bevacizumab in this neoplasm. The initial study reported was a randomized phase II trial (Figure 1) in which 116 patients with treatment-refractory, metastatic clear cell RCC received placebo, low dose $(3 \mathrm{mg} / \mathrm{kg}$ ) bevacizumab or high dose $(10 \mathrm{mg} / \mathrm{kg})$ bevacizumab given intravenously every 2 weeks. ${ }^{33}$ The majority of these patients were cytokine refractory, having received prior high dose interleukin (IL)-2. There were 4 partial responses, all in the high dose bevacizumab arm $(4 / 39 ; 10 \%$ objective response rate). A substantial proportion of patients, however, had tumor shrinkage not meeting objective response criteria. Figure 2 demonstrates tumor burden changes over time for each of the three patient cohorts, demonstrating a gradual positive effect on tumor burden with increasing doses of bevacizumab. ${ }^{34}$ An intent-to-treat analysis demonstrated a significant prolongation of time to progression in the high dose bevacizumab arm compared to placebo (4.8 vs 2.5 months; $P<0.001$ by log rank test). In the high dose bevacizumab arm, hypertension of any grade occurred in $36 \%$ of patients, and grade 3 hypertension, defined as hypertension not controlled by one standard medication, was observed in $21 \%$ of patients. Asymptomatic proteinuria without renal insufficiency was noted in $64 \%$ of patients in the high dose bevacizumab arm. All toxicities were reversible with cessation of therapy. The optimal duration of treatment with an agent such as bevacizumab was unclear, but preclinical studies had demonstrated VEGF maintained tumor 


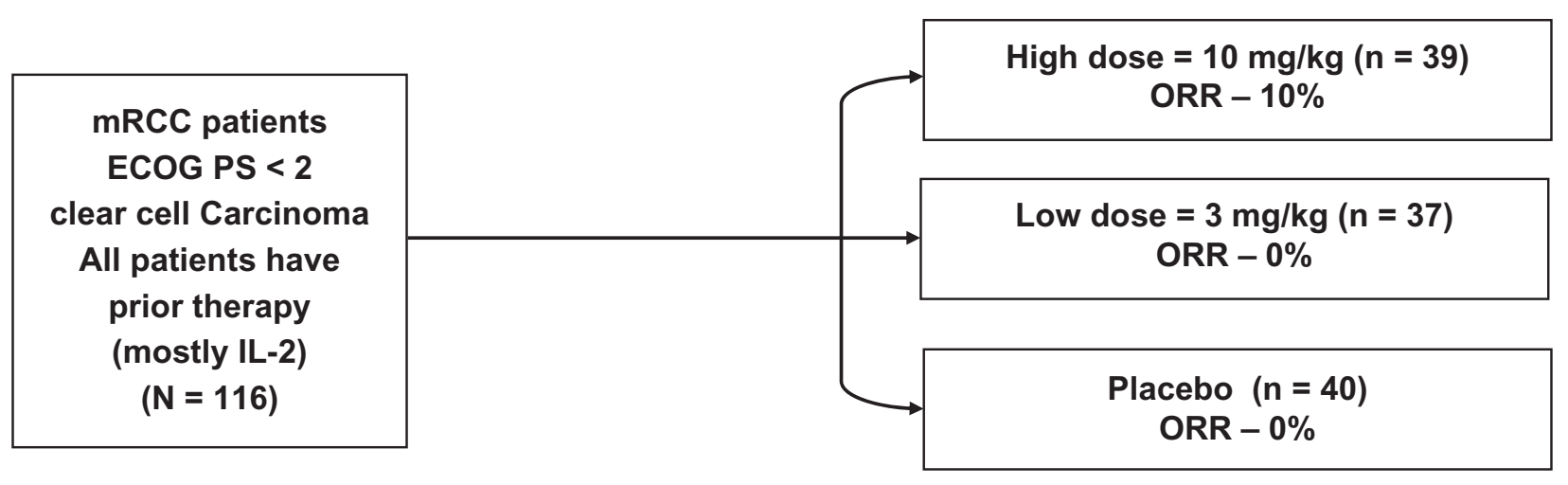

- $1^{\circ}$ end points: TTP and ORR

- $2^{\circ}$ end point: OS

- Study arms were balanced for demographics

Figure I Study schema for phase 2 randomized trial of bevacizumab or placebo in patients with previously treated metastatic renal cell carcinoma. Drawn from data of Yang JC et al. ${ }^{33}$

Abbreviations: ORR, overall response rate; TTP, time to progression; OS, overall survival.

vessel morphology, providing a rationale for continuous anti-VEGF therapy. ${ }^{35}$ In the study reported by Yang et $\mathrm{al}^{33}$ administration of bevacizumab was continued for over three years in four patients with prolonged disease stability. ${ }^{36}$ The toxicity in these patients was limited to proteinuria with normal renal function, and demonstrated long-term continuous administration was possible.

Bevacizumab was then investigated in combination with an anti-epidermal growth factor receptor (EGFR) inhibitor. Pre-clinical investigations in a human RCC xenograft model
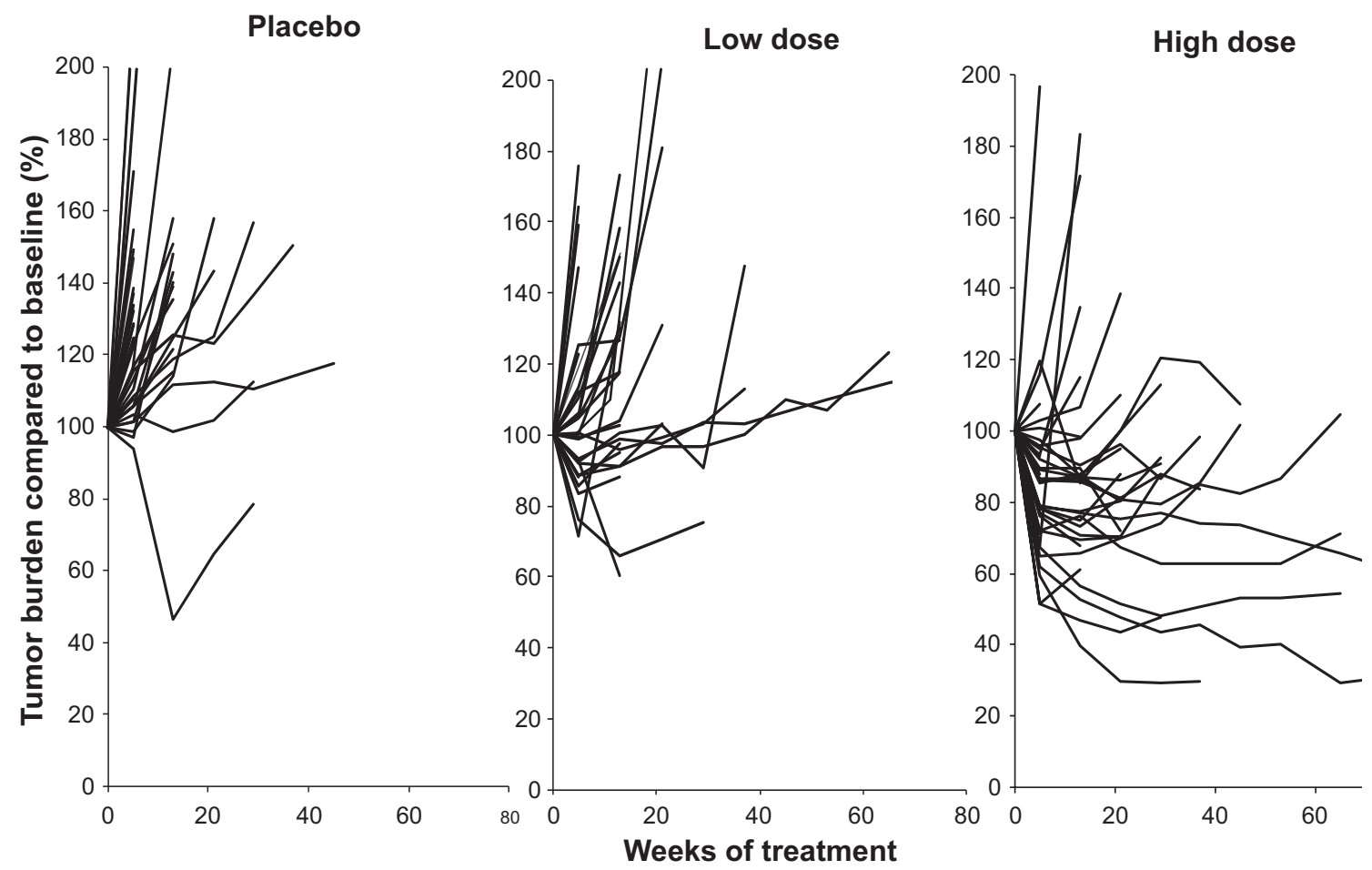

Figure 2 Phase 2 randomized trial of bevacizumab (low dose $-3.0 \mathrm{mg} / \mathrm{kg}$ iv every 2 weeks; high dose - $10.0 \mathrm{mg} / \mathrm{kg}$ iv every 2 weeks) or placebo. The individual panels illustrate the change in tumor burden expressed as percent compared to baseline over time (weeks of treatment). Each line represents an individual patient. The findings demonstrate the higher frequency of tumor reduction in the patients receiving high dose bevacizumab.

Drawn from data of Elaraj et al. ${ }^{34}$ 
demonstrated treatment with bevacizumab and erlotinib, a small molecule EGFR inhibitor, produced tumor growth inhibition. ${ }^{37}$ TGF- $\alpha$ is a VHL-regulated growth factor for RCC, with biologic effects mediated through EGFR. ${ }^{38}$ In view of these observations, a phase 2 clinical trial in metastatic RCC with bevacizumab $10 \mathrm{mg} / \mathrm{kg}$ IV every 2 weeks in combination with erlotinib $150 \mathrm{mg}$ daily was conducted. ${ }^{39}$ A 25\% objective response rate and $61 \%$ stable disease rate was noted with many of the stable disease patients experiencing minor tumor regression. After a median follow-up of 15 months, survival at 18 months was $60 \%$. Treatment associated adverse events were generally mild to moderate. The most common severe toxicities included rash (13\%), diarrhea (13\%) and hypertension (8\%).

A second phase $1 / 2$ trial employed combined VEGF, EGFR and PDGF-R blockade, and utilized combined bevacizumab $10 \mathrm{mg} / \mathrm{kg}$ IV every 2 weeks, erlotinib $150 \mathrm{mg}$ by mouth daily, and imatinib $400 \mathrm{mg}$ by mouth daily. ${ }^{40}$ The investigators reported a $9 \%$ response rate with $61 \%$ disease stabilization by RECIST criteria. Although tolerable for most patients, the toxicity was increased when compared to the experience with two agents, bevacizumab and erlotinib. In particular, the frequency and severity of grade 3 and 4 diarrhea (29\%) and acneiform skin rash $(27 \%)$ were increased with the addition of imatinib.
Since previous reports in which EGFR inhibitors alone were administered to patients with metastatic RCC did not demonstrate clinical activity, ${ }^{41}$ and these combination studies were interpreted as suggesting potential synergistic activity of bevacizumab and erlotinib.

Based on these preliminary reports ${ }^{39,40}$ a randomized, multicenter, double-blind phase 2 trial (Figure 3) at 21 sites in the United States, was conducted to further evaluate the efficacy of this combination as first-line therapy for metastatic RCC. ${ }^{42}$ Eligibility criteria included predominant (>50\%) clear cell histology, prior nephrectomy, measurable disease, and required patients to have either favorable or intermediate Memorial Sloan-Kettering Cancer Center (MSKCC) prognostic category. ${ }^{43}$ Treatment included bevacizumab 10 $\mathrm{mg} / \mathrm{kg}$, IV every 2 weeks, and either oral erlotinib $150 \mathrm{mg}$ or a placebo until progression, toxicity, or for a maximum of 104 weeks. The primary endpoints were progression-free survival (PFS) and overall response rate (ORR). One hundred and four patients were enrolled (Figure 3), and the median follow-up was 9.8 months. Median PFS was similar in the two treatment arms: 8.5 months with bevacizumab alone and 9.9 months for the combination (hazard ratio $[\mathrm{HR}]=0.86, P=0.58$ ). At 12 months from time of randomization, $40 \%$ of patients in the bevacizumab arm versus $45 \%$ in the bevacizumab plus erlotinib arm were progression-free. The pooled median PFS for the 104 patients entered was 8.6 months. Objective response

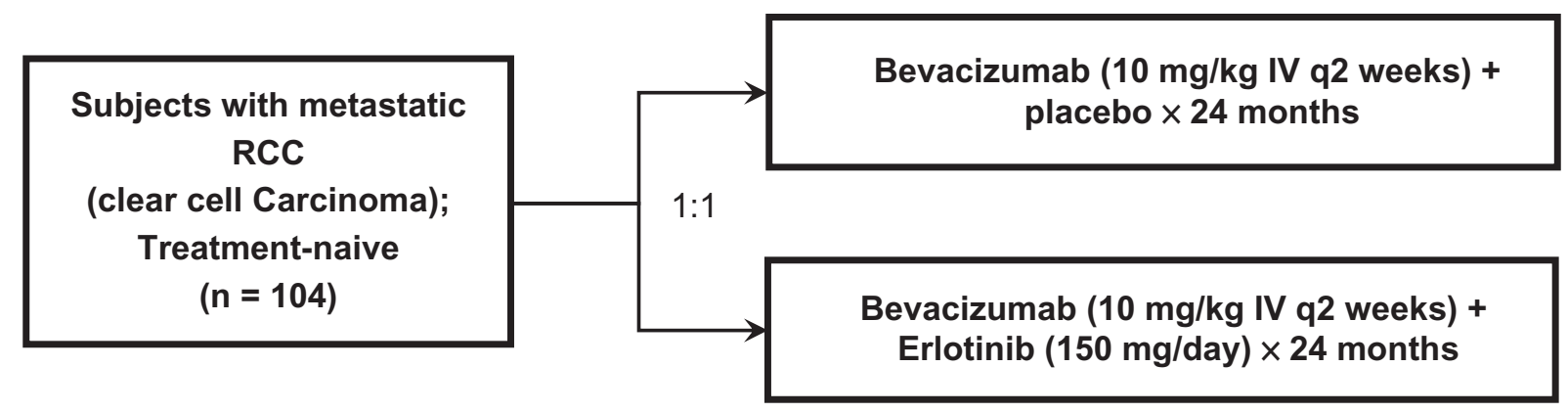

- Primary endpoints: PFS and ORR

- Landmark analysis at 9 months after last patient enrolled to estimate PFS and ORR (by RECIST)

- Secondary endpoints:

- Duration of response, overall survival, time to symptom progression

- Treatment duration - 104 weeks

Figure 3 Study schema for phase 2 randomized trial of bevacizumab plus placebo versus bevacizumab plus erlotinib in patients with treatment-naïve metastatic renal cell carcinoima.

Drawn from data of Bukowski et al. ${ }^{41}$

Abbreviations: PFS, progression-free survival; ORR, overall response rate. 
rates were also similar in the arms: $13 \%$ versus $14 \%$ respectively $(P=1.0)$. At 12 months from randomization, $83 \%$ of patients treated with bevacizumab were alive, versus $70 \%$ for patients receiving the combination.

Treatment was well tolerated, and only one therapy-related death occurred. The most common Grade 3/4 adverse events ( $>5 \%$ of patients) were hypertension, rash, diarrhea, and proteinuria. Adverse events associated with erlotinib (rash, diarrhea) were observed only in the arm containing erlotinib ( $16 \%$ and $7.8 \%$ of patients, respectively). Similar rates of hypertension and proteinuria, known toxicities associated with bevacizumab, were present in the two treatment arms. No evidence of enhanced toxicity was apparent. This study suggested one or more of the following: 1) erlotinib does not add to the efficacy of bevacizumab, 2) single-agent activity of bevacizumab has been underestimated, and/or 3 ) the randomized phase 2 trial design was underpowered to detect a small benefit with combination therapy. The role of bevacizumab in RCC remained unclear, and subsequently a series of phase 3 trials were conducted that clearly demonstrated its clinical activity.

\section{Phase 3 trials}

The phase 3 trials investigating bevacizumab in advanced clear cell carcinoma patients were then conducted utilized combination therapy with IFN- $\alpha$, and conclusively demonstrated the activity of this antibody (Figure 4). In the US, an Intergroup phase 3 open label trial (CALGB 90206) investigating the addition of bevacizumab to IFN- $\alpha$ has been reported, ${ }^{6}$ and in Europe, a similar trial which, however, was blinded and placebo controlled (AVOREN) ${ }^{5}$ has been reported. The data from this latter study supported the approval of bevacizumab plus IFN- $\alpha$ treatment for metastatic RCC by both the Food and Drug Administration (FDA) and the European Medicines Agency (EMEA).

CALGB $90206^{6}$ was a two-arm open-label study in which patients with metastatic clear cell RCC without prior systemic therapy were randomized to either low dose IFN- $\alpha 2 b$ (Intron ${ }^{\circledR}$ A; Schering-Plough, Kenilworth, NJ, USA), 9 MIU subcutaneously 3 times weekly, or the same dose and schedule of IFN$\alpha 2 \mathrm{~b}$ in combination with bevacizumab, $10 \mathrm{mg} / \mathrm{kg}$ IV every 2 weeks. Preliminary preclinical or clinical data demonstrating enhanced efficacy were not available, and the two agents were empirically combined. The primary endpoint of the trial was overall survival, and it was designed to detect an improvement from 13 months with IFN- $\alpha$ alone, to 17 months for the combination. Secondary endpoints included PFS, ORR, and safety. The study was reported before the primary endpoint was reached, when preliminary results from the AVOREN trial ${ }^{5}$

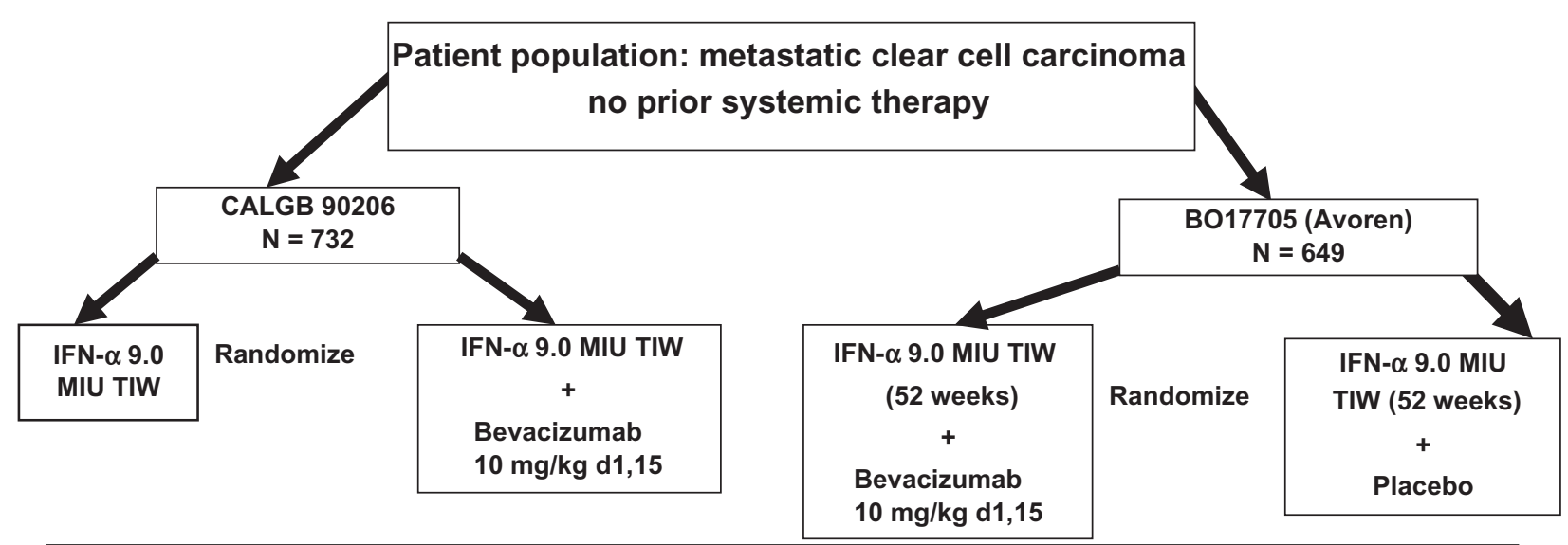

\begin{tabular}{|c|c|c|c|c|}
\hline & \multicolumn{2}{|c|}{ CALGB 90206 } & \multicolumn{2}{c|}{ AVOREN $^{\mathrm{a}}$} \\
\hline Therapy (arm) & IFN- $\alpha$ & $\begin{array}{c}\text { IFN- } \alpha+ \\
\text { bevacizumab }\end{array}$ & $\begin{array}{c}\text { IFN- } \alpha+ \\
\text { bevacizumab }\end{array}$ & IFN- $\alpha+$ placebo \\
\hline$\%$ ORR & $13.1 \%$ & $25.5 \%$ & $31.0 \%$ & $13.0 \%$ \\
\hline Median PFS & $5.2 \mathrm{mos}$ & $8.5 \mathrm{mos}^{\mathrm{a}}$ & $10.2 \mathrm{mos}$ & $5.4 \mathrm{mos}$ \\
\hline Median OS & $17.4 \mathrm{mos}^{\mathrm{c}}$ & $18.3 \mathrm{mos}^{\mathrm{c}}$ & $23.3 \mathrm{mos}^{\mathrm{d}}$ & $21.3 \mathrm{mos}^{\mathrm{d}}$ \\
\hline
\end{tabular}

Figure 4 Treatment schema and results in phase 3 randomized trials utilizing interferon alpha (IFN- $\alpha$ ) with/without bevacizumab. Results of the two studies AVOREN and CALGB 90206 are illustrated, demonstrating overall response rates (ORR), median progression-free survival (PFS), and median overall survival (OS).

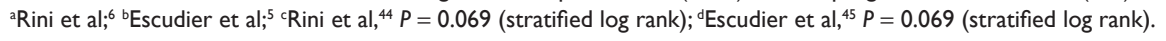


became available and demonstrated improvement of PFS for patients treated with the combination regimen. At that point, the CALGB Data Safety Monitoring Board recommended release of the PFS data. The median PFS was 8.5 months $(95 \%$ confidence interval [CI] 8.3-14.8) in patients receiving bevacizumab plus IFN- $\alpha$ versus 5.2 months (95\% CI 5.6-11.4) for IFN- $\alpha$ monotherapy $(P<0.0001)$. The hazard ratio for progression in patients receiving bevacizumab plus IFN- $\alpha$ after adjusting for stratification factors was $0.71(P<0.0001)$. In 639 patients with measurable disease, the ORR was higher in those receiving bevacizumab plus IFN- $\alpha$ (25.5\%; $95 \%$ CI $20.9 \%-30.6 \%$ ) compared to individuals treated with IFN- $\alpha$ alone $(13.1 \%$; 95\% CI 9.5\%-17.3\%; $P<0.0001)$. The combination however, produced an increased frequency of adverse events compared to cytokine therapy alone. Increased fatigue, anorexia, hypertension and proteinuria were reported. The survival data from this trial were recently updated..$^{43}$ The median OS was 18.3 months (95\% CI 16.5-22.5) for patients randomized to bevacizumab plus IFN- $\alpha$ and 17.4 months (95\% CI 14.4-20.0, unstratified $\log \operatorname{rank} P=0.097$ ) for IFN- $\alpha$ monotherapy group. The stratified HR was 0.86 (95\% CI 0.73-1.01) for the combination compared to IFN- $\alpha$ alone (stratified $\log$-rank $P=0.069$ ). Survival in the various MSKCC prognostic groups was also reported. In the favorable group, the median OS for bevacizumab plus IFN- $\alpha$ versus IFN- $\alpha$ was 32.5 versus 33.5 months $(P=0.524)$. In MSKCC intermediate risk patients, the respective median OS were 17.7 versus 16.1 months $(P=0.174)$, in poor risk patients 6.6 versus 5.7 months $(P=0.245)$. The final median PFS in both treatment groups was reported as 8.4 months versus 4.9 months $(P<0.0001)$. Fifty-three percent of patients received subsequent second-line systemic therapy.

These results were similar to those reported by the AVOREN investigators. ${ }^{5}$ This trial design was more robust, and differences included a double blind design, inclusion of a placebo infusion, gradual dose escalation of IFN- $\alpha$ over 3 weeks, requirement for prior nephrectomy, and the presence of predominantly clear cell carcinoma in the AVOREN study. Results from these two studies are compared in Table 1. In both trials, patients treated with IFN- $\alpha$ plus bevacizumab appeared to benefit, with significant increases in median PFS and ORR noted. The magnitude of improvement seen was slighty different, but the varied eligibility criteria and patient distribution between prognostic categories, as well as variations in experimental design, can potentially explain these findings. Of interest, subset analyses in both trials failed to demonstrate improved PFS for the poor risk patient subset, which represented a very small group $(<10 \%)$ in
Table I Risk group survivals in phase 3 bevacizumab trials

\begin{tabular}{|c|c|c|c|c|}
\hline \multirow{3}{*}{$\begin{array}{l}\text { Risk group } \\
(\text { MSKCC) })^{\mathrm{a}}\end{array}$} & \multicolumn{2}{|c|}{ Progression-free survival* } & \multicolumn{2}{|c|}{ Overall survival* } \\
\hline & AVOREN $^{b}$ & $\overline{\text { CALGB } 90206^{c}}$ & AVOREN & CALGB \\
\hline & & & & $90206^{d}$ \\
\hline \multicolumn{5}{|l|}{ Favorable } \\
\hline $\begin{array}{l}\text { Bevacizumab + } \\
\text { IFN- } \alpha\end{array}$ & $12.9 \mathrm{mos}$ & $11.1 \mathrm{mos}$ & NA & $32.5 \mathrm{mos}$ \\
\hline IFN- $\alpha$ & $7.6 \mathrm{mos}$ & $5.7 \mathrm{mos}$ & NA & $33.5 \mathrm{mos}$ \\
\hline \multicolumn{5}{|l|}{ Intermediate } \\
\hline $\begin{array}{l}\text { Bevacizumab + } \\
\text { IFN- } \alpha\end{array}$ & $10.2 \mathrm{mos}$ & $8.4 \mathrm{mos}$ & NA & $17.7 \mathrm{mos}$ \\
\hline IFN- $\alpha$ & $4.5 \mathrm{mos}$ & $5.3 \mathrm{mos}$ & NA & $16.1 \mathrm{mos}$ \\
\hline \multicolumn{5}{|l|}{ Poor } \\
\hline $\begin{array}{l}\text { Bevacizumab + } \\
\text { IFN- } \alpha\end{array}$ & $2.2 \mathrm{mos}$ & $3.3 \mathrm{mos}$ & NA & $6.6 \mathrm{mos}$ \\
\hline IFN- $\alpha$ & $2.1 \mathrm{mos}$ & $2.6 \mathrm{mos}$ & NA & $5.7 \mathrm{mos}$ \\
\hline
\end{tabular}

*Median; NA - not available.

${ }^{a}$ Motzer et al ${ }^{43}$; bescudier et al $\left.\right|^{5}$; Rini et al ${ }^{6}$; 'Rini et al. ${ }^{44}$

both trials. Based on the AVOREN data, the combination of bevacizumab plus IFN- $\alpha$ has been approved for the treatment of patients with metastatic RCC by both the EMEA and FDA (after independent radiology review). The final AVOREN survival data have also been reported.$^{45}$ At the time of this analysis median follow-up was over 20 months in each $\mathrm{arm}$. The final median OS stratified for region and MSKCC prognostic group was 23.3 months for patients treated with in bevacizumab + IFN- $\alpha$, versus 21.3 months in the IFN- $\alpha$ and placebo arm (HR 0.86 [95\% CI 0.72-1.04], $P=0.1291$ ). No new or unexpected adverse events were observed. More patients in the IFN- $\alpha$ plus placebo arm $(202,63 \%)$ received post-protocol therapy than in the combination arm (180, $55 \%$ ). Treatments included tyrosine kinase inhibitors (TKI), mTOR inhibitors, cytokines and chemotherapy. Exploratory analysis demonstrated the median OS in pts receiving secondline TKI therapy was 38.6 months in patients initially treated with bevacizumab plus IFN- $\alpha(n=96)$ versus 33.2 months in the IFN- $\alpha$ patient group $(\mathrm{n}=81)(\mathrm{HR}=0.77[95 \% \mathrm{CI}$ $0.51-1.15], P=0.1948$ ).

These results demonstrate clinical benefit for patients receiving combination therapy, but as is usually the case, raise additional questions. The activity of bevacizumab in combination with IFN- $\alpha$ in patients with metastatic clear cell carcinoma is clear; however, dose levels of both agents, length of therapy, and the role of IFN- $\alpha$ are not addressed except indirectly. In the United States, the FDA suggested the CALGB 90206 study incorporate a third treatment arm utilizing bevacizumab alone, to isolate the effects of both agents. Unfortunately, this advice was not followed, and therefore, 
the potential contributions of each agent are unclear. In view of the previous phase 2 data with bevacizumab monotherapy in untreated patients, ${ }^{42}$ in which a median PFS in excess of 9.0 months was noted, it is reasonable to suggest the major contribution to efficacy in terms of PFS improvement, may be secondary to this agent.

Additionally, preclinical data are not available that address the mechanisms potentially responsible for the interactions of these two agents. Bevacizumab and IFN- $\alpha$ may have complementary effects on tumor growth as well as the antitumor immunologic response. The concept of immune dysfunction related to both local and systemic immunosuppression has been repeatedly demonstrated in advanced $\mathrm{RCC} .{ }^{46}$ In preclinical studies, VEGF inhibits the maturation and function of dendritic cell, ${ }^{47}$ and IFN- $\alpha$ can induce maturation and cytokine production ${ }^{48}$ by this cell population. The possibility that anti-VEGF therapy combined with IFN- $\alpha$ may interact to decrease immune suppression is an attractive hypothesis. Finally, since both bevacizumab and low doses of IFN- $\alpha$ have antiangiogenic activity, ${ }^{49}$ the interaction may be at this level. The exact nature of this interaction in RCC patients is, however, unclear, as is the contribution of each agent individually to the clinical results.

In terms of the toxicity produced by bevacizumab plus IFN- $\alpha$, the adverse events appear related to both agents. In the AVOREN trial, ${ }^{5}$ the most commonly reported grade 3 or worse adverse events were established IFN- $\alpha$ toxicities (eg, fatigue, asthenia, and neutropenia). Adverse events occurred in $328(97 \%)$ of those patients who received at least one dose of bevacizumab and 287 (94\%) of those who did not receive bevacizumab. Serious adverse events ( $\geq$ grade 3 ) were reported in 98 (29\%) patients who received bevacizumab and 50 (16\%) of those receiving a placebo. The proportion of patients who experienced an adverse event that led to treatment discontinuation $(28 \%)$ was higher in the bevacizumab plus interferon alfa group than in the control group. The incidence of interferon-related toxicities was reported as $10 \%$ higher per patient-year in the bevacizumab plus interferon alfa group than in the control group. Bevacizumab-related toxicities (eg, proteinuria, bleeding, and hypertension) were seen in the bevacizumab plus IFN- $\alpha$ group only.

The dose of IFN- $\alpha$ utilized in the AVOREN trial was 9 MIU 3 times a week. ${ }^{5}$ Investigators were permitted to gradually escalate IFN- $\alpha$ from 3.0 to 9.0 MIU over a 3-week period. During the course of treatment, IFN- $\alpha$ dose reduction and/or delay was permitted for $\geq$ grade 3 toxicity. The IFN- $\alpha$ dose was reduced to 6.0 or $3.0 \mathrm{MU}$ in $124(40 \%)$ patients in the bevacizumab plus IFN- $\alpha$ group and 94 (30\%) patients in the control group. An exploratory analysis ${ }^{50}$ demonstrated patients receiving a reduced dose of IFN- $\alpha$ (either 3.0 or 6.0 MIU) also benefited from treatment. Although IFN- $\alpha$ related grade $3 / 4$ toxicity was predefined as a requirement for IFN- $\alpha$ dose reduction, it was reported in only $44 \%$ and $41 \%$ of patients in the bevacizumab and placebo groups, respectively, in the 6 weeks prior to IFN- $\alpha$ dose reduction. In the majority of cases, the IFN- $\alpha$ dose was reduced for reasons other than grade $3 / 4$ toxicity, including the accumulation of grade 2 IFN- $\alpha$ related events, or based on physician or patient preference.

Of those patients who received reduced doses of IFN- $\alpha$, $64 \%$ underwent 1 dose reduction (to $6 \mathrm{MIU}$ ), $31 \%$ underwent 2 dose reductions (to $6.0 \mathrm{MIU}$, then to $3.0 \mathrm{MIU}$ ) and $5 \%$ dose-reduced directly to 3.0 MIU. Patients in the dose reduction group spent $62 \%$ of the total IFN- $\alpha$ treatment duration at 6.0 or 3.0 MIU. Analysis of all patients demonstrated the median duration of PFS in patients receiving bevacizumab plus IFN- $\alpha$ was double that of patients receiving IFN- $\alpha$ plus placebo $(\mathrm{HR}=0.63, P<0.0001)$. An exploratory analysis also showed a similar improvement in PFS for patients receiving reduced IFN- $\alpha$ doses $(\mathrm{HR}=0.63, P=0.0026)$ and those treated with 9.0 MIU $(\mathrm{HR}=0.69, P=0.0007)$.

PFS rates at 12 months for patients receiving bevacizumab plus IFN- $\alpha$ were 0.524 for the reduced-dose group (95\% CI $0.436-0.613), 0.427$ for the total population $(95 \%$ CI $0.372-0.483)$, and 0.361 for patients maintaining the 9.0 MIU IFN- $\alpha$ dose level (95\% CI 0.292-0.431). The 12-month PFS rate was similar in patients who were dose reduced to $3.0 \mathrm{MIU}$ IFN (0.668 [95\% CI 0.512-0.824]). These data are consistent with previous observations suggesting IFN- $\alpha$ efficacy in patients with metastatic RCC is not dose related, and indicate lower doses of IFN- $\alpha$ should be combined with bevacizumab in future studies.

The pattern of adverse event (AE) reporting demonstrated the majority of grade 3 AEs occurred during the first 3 months of treatment. A reduction in $\geq$ grade 3 AEs was observed in the 6 -week period after IFN- $\alpha$ dose reduction in contrast to the 6 weeks prior to dose reduction in the group receiving bevacizumab plus reduced-dose IFN- $\alpha$ (44\% vs 18\%) and reduced-dose IFN- $\alpha$ plus placebo (41\% vs $10 \%)$. This trend toward improved safety was consistent across the MSKCC risk categories. In view of the recognized lack of IFN- $\alpha$ dose-response in RCC, it appears that lower doses will result in less toxicity, and possibly preserve efficacy.

The final overall survival analysis has been completed for both CALGB 90206 and the AVOREN trials. ${ }^{44,45}$ The data 
do not demonstrate significant improvements in median OS in either trial, but as in other recently published analyses of other targeted agents, ${ }^{51}$ may be confounded by secondary therapy. The effects of bevacizumab plus IFN- $\alpha$ compared to IFN- $\alpha$ alone on PFS and median OS in the various MSKCC prognostic subgroups are also of interest (see Table 1). The subgroup analyses show the major effects are in the favorable and intermediate subgroups. The poor risk patient subset shows limited if any effect of adding bevacizumab to IFN- $\alpha$, but this group represents $<10 \%$ of patients in each trial. The overall survival subset analyses from CALGB 90206 shows improvement in the intermediate group, but none in the favorable and poor risk categories. This is similar to the reported effects of sunitinib on median OS in the favorable patient subset, and raises the issue of why no differences were seen between IFN- $\alpha$ monotherapy and either sunitinib or bevacizumab plus IFN- $\alpha$. Explanations again include the confounding effects of secondary therapy, as well as the indolent behavior RCC clinically and the as yet undefined biologic and molecular characteristics of this RCC subtype.

\section{Pharmacoeconomic analyses}

In view of the costs associated with targeted therapy for advanced RCC patients, it is reasonable to expect improvement in survival as an indicator of benefit. The confounding effects of secondary therapy have, however, made results from these analyses problematic. CALGB 90206 had as its primary endpoint OS, and, the overall survival of the IFN- $\alpha$ treated group appears greater than anticipated. ${ }^{43}$ In recently reported phase 3 studies utilizing either sorafenib ${ }^{50}$ or sunitinib, ${ }^{51}$ the increased PFS was not accompanied by significant improvement in OS. In the trial comparing sunitinib and IFN- $\alpha,{ }^{51}$ the differences in median OS in the intent to treat population was considered clinically significant, despite the $P$ value of 0.051 . When patients receiving secondary therapy were censored, significant differences were noted. It is likely the same confounding effects of secondary therapy are obscuring differences in survival in the recent phase 3 bevacizumab trials. The available clinical data from three randomized clinical trials demonstrate therapy with sunitinib or bevacizumab plus IFN- $\alpha$ produces clinically relevant and a statistically significant increase in PFS compared to treatment with IFN- $\alpha$ monotherapy.

Another unanswered question is how bevacizumab plus IFN- $\alpha$ therapy compares to the current front line treatment for metastatic RCC with sunitinib. The toxicity of sunitinib and bevacizumab are quite different, however, when IFN- $\alpha$ is included, the type and frequency of adverse events is modified.
Currently, no phase 3 trials are planned or are in progress to compare efficacy and/or toxicity of these treatments, and therefore only indirect comparisons are possible. Coon et $\mathrm{al}^{53}$ have utilized an indirect comparison methodology to assess the clinical effectiveness of sunitinib or bevacizumab plus IFN-a on PFS. A Bayesian Marko Chain Monte-Carlo sampling model in Win BUGS, with IFN- $\alpha$ as a common comparator was employed. The median PFS was significantly prolonged with either regimen compared to IFN- $\alpha$. Indirect comparison suggested sunitinib was superior to bevacizumab plus IFN- $\alpha$ in terms of PFS (HR 0.796; 95\% CI 0.63-1.0; $P=0.0272$ ). Indirect survival comparisons have not yet been published.

Pharmacoeconomic assessment of targeted therapy as frontline treatment for metastatic RCC in the US and Sweden have been conducted utilizing indirect comparisons of survival. ${ }^{54}$ A Markov model was employed which simulated disease progression, adverse events, and survival with sunitinib versus sorafenib (US) or bevacizumab + IFN- $\alpha$ (both countries) among all patients. Results, in life-years (LY), progression-free LY (PFLY), quality-adjusted LY (QALY) gained, and treatment costs were developed employing deterministic and probabilistic analyses. Sunitinib was more effective and less costly than sorafenib (gains of 0.52 PFLY, $0.16 \mathrm{LY}$, and 0.17 QALY and savings of \$13,576 in the US) or bevacizumab + IFN- $\alpha$ (gains of 0.19 PFLY, 0.23 LY, and 0.16 QALY in both countries and savings of $\$ 67,798$ and $\$ 47,264$ in the US and Sweden, respectively). Sunitinib was shown to be cost effective in comparison to other therapies in either the US or Sweden, despite significant differences in healthcare systems. In fact, sunitinib was found to be more effective and less costly compared to bevacizumab + IFN- $\alpha$ in the overall patient population in both countries.

These two regimens have different toxicity profiles, and therefore it has been hypothesized that costs for managing adverse events may be different. Mickisch et $\mathrm{al}^{55}$ used a linear decision analytical model to evaluate cost differences associated with AE management during treatment with bevacizumab plus IFN- $\alpha$ or sunitinib. Costs were calculated utilizing published data on health-care costs in the United Kingdom, Germany, France and Italy. The analysis suggested AE management costs were higher for sunitinib than for bevacizumab plus IFN- $\alpha$. The average cost per patient for the management of grade 3-4 adverse events was decreased with bevacizumab plus IFN- $\alpha$ compared with sunitinib in all countries: United Kingdom $€ 1475$ versus $€ 804$, Germany $€ 1785$ versus $€ 1367$, France $€ 2590$ versus $€ 1618$, and Italy $€ 891$ versus $€ 402$. The main determinants were lymphopenia, neutropenia, thrombocytopenia, leukopenia fatigue, and asthenia for sunitinib, 
and for bevacizumab plus IFN- $\alpha$, proteinuria, fatigue, asthenia, bleeding, anemia and gastrointestinal perforation. The authors concluded costs associated with adverse event management are lower for bevacizumab plus IFN- $\alpha$ than for sunitinib. It is unclear however, how therapy for lymphopenia can contribute significantly to treatment costs.

Similarly, as part of its health technology appraisal, the National Institute for Health and Clinical Excellence (NICE) in the UK also examined the cost-effectiveness of sunitinib and bevacizumab + IFN- $\alpha$ compared to IFN- $\alpha$. Based on multiple considerations, including but not limited to costeffectiveness evidence, NICE recommended sunitinib as first-line treatment for people with advanced and/or metastatic RCC who are suitable for cytokine therapy and who have an ECOG performance status of 0 or $1 .{ }^{56}$ The findings of the NICE cost-effectiveness analyses were also consistent with those reported by Benedict et al. ${ }^{54}$

Modeling treatments that have not been compared in randomized prospective trials, and subsequent extrapolation of their outcomes, represents a significant challenge. Such findings may be considered robust if they are based on valid assumptions including treatment of similar patient populations. Studies such as these do however have significant limitations which include: (1) the confounding effect of crossover treatment on OS, which may inflate the outcome for a comparator group and underestimate the treatment benefit; (2) the uncertainty of assuming that the relative HR values for a given treatment, relative to comparator, remain constant over time; and (3) differences in survival between patients treated in clinical trials and in clinical practice.

\section{Bevacizumab: future development in RCC}

The future development of bevacizumab therapy in renal cell carcinoma is illustrated in Figure 5. The role of monotherapy remains to be fully assessed, and further development of combination strategies should be considered. The activity of bevacizumab plus IFN- $\alpha$ in patients with metastatic clear cell carcinoma has been clearly demonstrated, however, various dose levels of either agent, length of therapy, and the role of IFN- $\alpha$ in the combination have not been investigated adequately. The mechanisms responsible for the activity of this combination remain uncertain. Also, in view of the recognized lack of IFN- $\alpha$ dose-response in RCC, it may be that lower doses can decrease toxicity while preserving efficacy.

Since bevacizumab has been successfully combined with IFN- $\alpha$, it is reasonable to investigate the combination

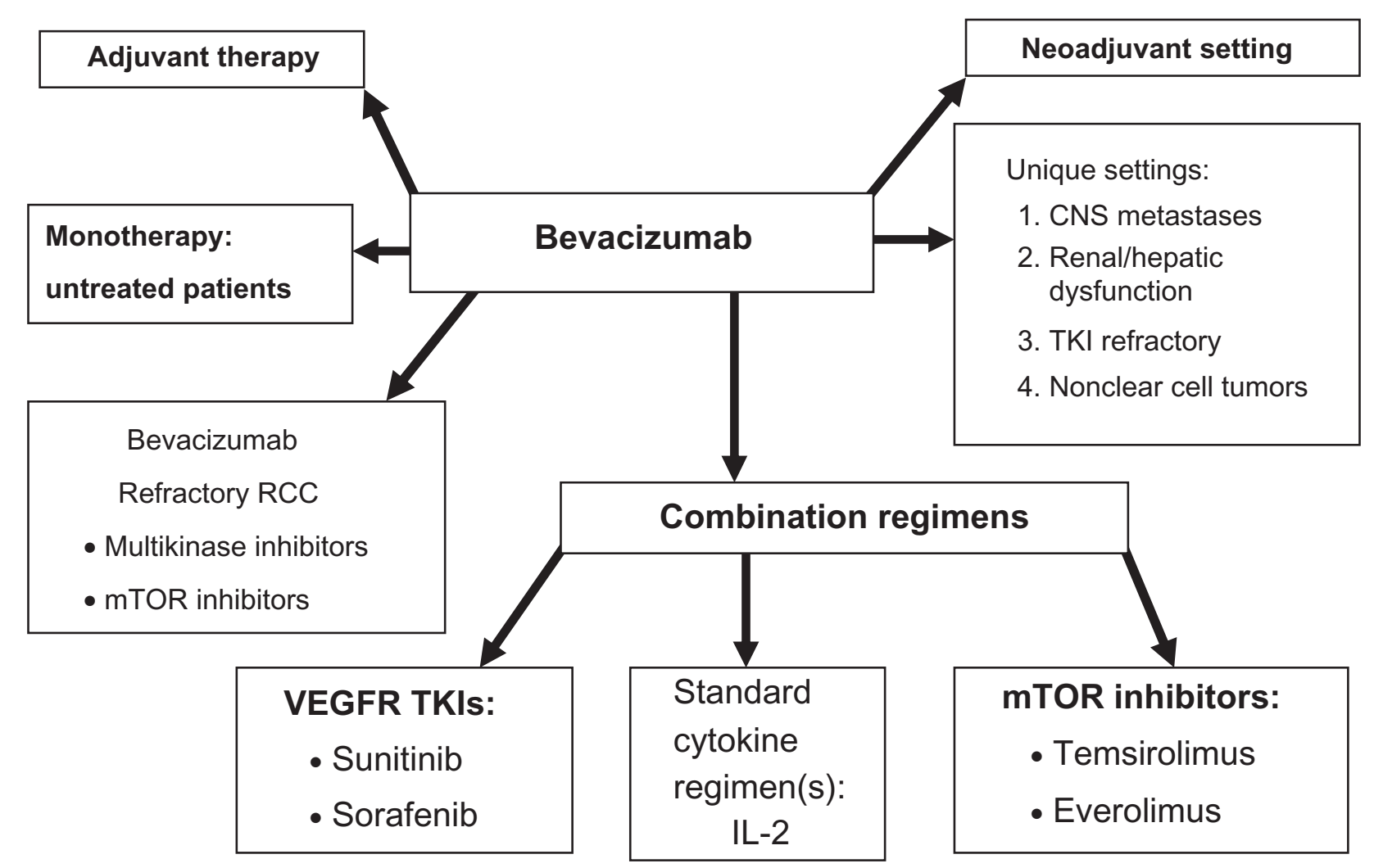

Figure 5 Diagram illustrating potential future clinical studies with bevacizumab in patients with renal cell carcinoma. 
of bevacizumab with other cytokines, such as IL-2. High-dose IL-2 in combination with bevacizumab is under investigation. ${ }^{57}$ The rationale for this combination includes the possibility that bevacizumab may prevent much of the tumor-induced immunosuppression attributed to VEGF and thereby enrich the immune-enhancing effects of IL-2. ${ }^{58}$ In addition, IL-2 toxicity may be reduced by the vascular effects of bevacizumab on the vascular leak syndrome, and possibly allow more IL-2 to be administered with less toxicity. Bevacizumab $10 \mathrm{mg} / \mathrm{kg}$ IV every 2 weeks will be integrated with standard high dose IL-2 regimens with both PFS and OS as primary endpoints.

Investigation of bevacizumab in combination with low dose IL-2 has also been initiated. Garcia et al ${ }^{59}$ reported 26 patients with untreated advanced $\mathrm{RCC}$ who received bevacizumab $10 \mathrm{mg} / \mathrm{kg}$ every 2 weeks, and IL-2 125,000 u/kg/day subcutaneously for 6 weeks, followed by a 2 -week rest period. The median PFS for the group was 9.6 months $(95 \%$ CI 4.1-16.9 months), and ORR 15\%. An additional 38\% of patients achieved tumor burden reduction of $<30 \%$. The most commonly reported treatment-related grade 3 toxicities were constitutional (fatigue, fever/chills) in $46 \%$ of patients, neutropenia in $11 \%$ and proteinuria in $12 \%$ of patients. The authors conclude that bevacizumab plus low dose IL-2 has modest clinical activity, and toxicity was largely IL-2 related without enhancement of bevacizumab-related adverse events.

Despite recent advances in the treatment of advanced $\mathrm{RCC}$, not all patients respond, complete responses are uncommon, and tumor resistance to VEGF-targeted therapy generally develops. In view of these observations, maximal inhibition of the VEGF pathway, with combinations of VEGFtargeting agents having different mechanisms, may produce enhanced anti-tumor effects. Additive or synergistic VEGF blockade may be achieved through simultaneous targeting of the VEGF pathway. Bevacizumab leads to rapid clearance of circulating VEGF, but is not known to affect VEGF bound to receptor, as the epitope on VEGF recognized by bevacizumab is in the VEGF-R binding region. Further, other pro-angiogenic molecules such as PDGF may contribute to the angiogenic phenotype of RCC and require inhibition. Sunitinib produces VEGF receptor blockade, however, circulating plasma VEGF increase and may expose tumors to the effects of VEGF in view of the intermittent schedule utilized. ${ }^{60}$ It is possible that maximal, constant and effective VEGF blockade can be produced with drugs inhibiting both the VEGF ligand and receptor, with enhanced anti-tumor effects. In view of this, combinations of bevacizumab with various TKIs such as sunitinib or sorafenib have been investigated.
Two phase 1 trials combining bevacizumab and sunitinib have have investigated the safety and maximum tolerated dose of this combination. ${ }^{61,62}$ Study design and eligibility criteria were different, with one trial ${ }^{61}$ restricted to advanced RCC patients, while in the second study, ${ }^{62}$ patients with refractory solid tumors were eligible. Antitumor activity was noted in both studies, but $\geq$ grade 3 hypertension was noted in 45 to $60 \%$ of patients, and full doses of both agents (bevacizumab $10 \mathrm{mg} / \mathrm{kg}$ every 2 weeks, sunitinib $50 \mathrm{mg} /$ day $4 / 2$ week schedule) were poorly tolerated. In the report from MSKCC, ${ }^{61} 5 / 25$ patients developed evidence of microangiopathic hemolytic anemia, in contrast to the second trial ${ }^{62}$ in which this was not observed. In view of these observations, further investigation of this combination in RCC utilizing full doses of both agents has not been recommended. ${ }^{61}$

The multikinase inhibitor sorafenib has also been investigated in combination with bevacizumab in a series of two phase 1 trials. ${ }^{63,64}$ Azad et al ${ }^{63}$ reported a group of 39 patients with advanced solid tumors who were treated in a phase 1 dose escalation trial utilizing bevacizumab and sorafenib. Dose-limiting toxicity included grade 3 proteinuria and thrombocytopenia. Adverse events included hypertension, hand-foot syndrome, diarrhea, hepatic toxicity, and fatigue. Partial responses were seen in six ( $43 \%)$ of 13 patients with ovarian cancer (response duration range, 4 to 22 months) and 1 of 3 patients with renal cell cancer (response duration, 14 months). The majority (74\%) of patients required sorafenib dose reduction. The investigators concluded combination therapy with sorafenib and bevacizumab has promising activity; however, dose reductions of both agents are required. Sosman et $\mathrm{al}^{64}$ also investigated this combination in 48 patients with RCC. Enhanced toxicity was observed, characterized by the sorafenib-related toxicity including severe hand-foot syndrome and functional stomatitis, and the bevacizumab related hypertension, and persistent proteinuria. Administration of the combination required decreasing both the bevacizumab $(5 \mathrm{mg} / \mathrm{kg}$ IV every 2 weeks) and sorafenib (200 mg by mouth once daily) dose levels. The clinical activity of the combination, was of interest in RCC, with an ORR of 52\%, and PFS of 14.0 months among the 48 RCC patients enrolled. In summary, the activity of the various bevacizumab TKI combinations is encouraging, but complete responses were not increased, and toxicity has required dose reductions of both agents. It remains uncertain whether combination approaches will be useful.

The second class of targeted agents that has been combined with bevacizumab, are the mTOR inhibitors temsirolimus and everolimus. Clinical trials in poor risk patients with temsirolimus, ${ }^{4}$ and in TKI refractory patients with everolimus ${ }^{65}$ 
demonstrate improvements in survival and PFS respectively. Preclinical studies ${ }^{66}$ have suggested combing an mTOR inhibitor with bevacizumab may increase efficacy, and therefore this combination has been evaluated clinically.

A phase 2 study by Whorf et $\mathrm{al}^{65}$ investigated the combination of bevacizumab and everolimus. Patients with advanced $\mathrm{RCC}$ received bevacizumab $10 \mathrm{mg} / \mathrm{kg}$ IV every 2 weeks and everolimus $10 \mathrm{mg}$ orally daily. Two groups of patients were treated: A-no prior treatment or B-prior sunitinib or sorafenib. Fifty-nine patients (30 to group A and 29 to group B) were enrolled. The best response in 48 evaluable patients was $21 \%$ ORR and $69 \%$ stable disease/minor response. Toxicities included proteinuria (19\% grade $3 / 4)$, fatigue (9\% grade $3 / 4$ ) mucositis/stomatitis (49\% grade 3/4), hyperlipidemia (45\% grade $3 / 4$ ), nausea (40\% grade $3 / 4$ ) and hypertension (25\%). The preliminary results suggest the combination of everolimus and bevacizumab administered at full doses has acceptable toxicity. A phase 2 randomized trial in which bevacizumab is combined with either IFN- $\alpha$ or everolimus (RECORD 2) is in progress.

Temsirolimus, the second mTOR inhibitor approved in advanced RCC, has also been combined with bevacizumab. A phase 1 trial ${ }^{67}$ utilizing both temsirolimus and bevacizumab was reported in a preliminary fashion. Dose-limiting toxicities encountered included grade 3 stomatitis and hypertryglyceridemia ( $1 / 6$ patients at each dose level). The minimum tolerated dose was not reached, and the dose levels recommended for additional study were temsirolimus $25 \mathrm{mg} / \mathrm{kg}$ IV weekly and bevacizumab $10 \mathrm{mg} / \mathrm{kg}$ every 2 weeks. Twelve evaluable patients were treated, and 7/12 partial responses (58\%) were reported. Based on these preliminary results, a randomized phase 3 trial (INTORACT) is now ongoing comparing temsirolimus/ bevacizumab with bevacizumab/IFN- $\alpha$. The studies with the mTOR inhibitors will provide information on the side effect profiles and efficacy of the mTOR inhibitor combinations investigated.Several other randomized trials evaluating various combinations are also underway. The BEST trial ${ }^{68}$ is a 4 -arm phase 2 randomized trial examining doublets of sorafenib, bevacizumab, and temsirolimus plus bevacizumab alone. The TORAVA trial is a phase 2 trial comparing bevacizumab plus IFN- $\alpha$, bevacizumab plus temsirolimus, and sunitinib. Enrolment is closed and results should be available shortly. ${ }^{69}$ Currently most investigators regard combination therapy as investigational. Results of these ongoing trials are should define the efficacy an mTOR inhibitor plus bevacizumab.

Two additional areas of investigation to be considered are post-operative adjuvant therapy, and preoperative neoadjuvant therapy with bevacizumab. Currently, several large multinational adjuvant trails utilizing the kinase inhibitors are in progress. When these results are available, comparison to bevacizumab is a strong consideration in view of the acceptable toxicity profile of this agent. In contrast, the potential role of bevacizumab in the neoadjuvant setting in patients with advanced RCC has been investigated. Jonasch et $\mathrm{al}^{70}$ assessed the safety and efficacy of presurgical treatment with bevacizumab in metastatic RCC patients, and whether this would assist in patient selection for cytoreductive nephrectomy. 50 patients with clear cell carcinoma received either bevacizumab plus erlotinib $(\mathrm{n}=23)$ or bevacizumab alone ( $n=27$ ) for 8 weeks followed by restaging. $42 / 50$ patients underwent nephrectomy. Median PFS was 11.0 months $(95 \%$ CI 5.5-15.6 months), and median OS 25.4 months (95\% CI 11.4 months to not evaluated). Wound dehiscence required treatment discontinuation for three and treatment delay for two other patients. The investigators concluded presurgical treatment with bevacizumab yields clinical outcomes comparable to postsurgical treatment, but it may result in wound-healing delays. Prospective, randomized trials are now required to test the value of neoadjuvant bevacizumab.

\section{Summary}

Bevacizumab is a humanized monoclonal antibody that binds specifically to VEGF and inhibits VEGF activity. It has significant clinical benefits in patients with common solid tumors, including metastatic colorectal carcinoma, ${ }^{71}$ metastatic breast carcinoma, ${ }^{72}$ and nonsmall cell lung carcinoma. ${ }^{73}$ The available data now clearly demonstrate reproducible effects and benefit in patients with metastatic RCC. A series of phase 2 trials demonstrated that bevacizumab monotherapy has activity and is well tolerated in patients with both therapy-naïve and pre-treated mRCC. ${ }^{33,42}$ In addition, experience from clinical trials indicates that bevacizumab does not increase the toxicity of concomitantly administered therapy. ${ }^{71-73}$ Bevacizumab and IFN- $\alpha$ suppress tumor growth by direct and indirect mechanisms, and these two agents may have complementary and synergistic effects when combined. The results from two recently completed phase 3 trials, demonstrate bevacizumab plus IFN- $\alpha$ is a clinically useful treatment option for patients with good/intermediate risk metastatic clear cell carcinoma of the kidney. ${ }^{5,6}$ When this regimen is employed, it should be administered as described in the recently published studies. ${ }^{5,6}$ The choice of therapy for individual patients should be based on perceived risk/benefit ratio as well as the adverse event profile of the therapy. In the future comparative studies will be needed to define standards of care and assist physicians and patients with these therapeutic decisions. 


\section{Disclosure}

The author is a consultant for Genentech, Pfizer, Novartis, and GSK; he has also received honoraria from these companies and from Bayer.

\section{References}

1. Jemal A, Siegel R, Ward E, et al. Cancer statistics, 2008. CA Cancer J Clin. 2008;58:71-96.

2. George DJ, Kaelin WG Jr. The von Hippel-Lindau protein, vascular endothelial growth factor, and kidney cancer. $N$ Engl $\mathrm{J} \mathrm{Med}$. 2003;349:419-421.

3. Motzer RJ, Hutson TE, Tomczak P, et al. Sunitinib versus interferon alfa in metastatic renal-cell carcinoma. $N$ Engl J Med. 2007;356:115-124.

4. Hudes G, Carducci M, Tomczak P, et al. Temsirolimus, interferon alfa, or both for advanced renal-cell carcinoma. N Engl J Med. 2007;356:22712281.

5. Escudier B, Pluzanska A, Koralewski P, et al. Bevacizumab plus interferon alfa-2a for treatment of metastatic renal cell carcinoma: a randomised, double-blind phase III trial. Lancet. 2007;370:2103-2111.

6. Rini BI, Halabi S, Rosenberg JE, et al. Bevacizumab plus interferon alfa compared with interferon alfa monotherapy in patients with metastatic renal cell carcinoma: CALGB 90206. J Clin Oncol. 2008;26:5422-5428.

7. Gnarra JR, Lerman MI, Zbar B, and Linehan WM. Genetics of renalcell carcinoma and evidence for a critical role for von Hippel-Lindau in renal tumorigenesis. Semin Oncol. 1995;22:3-8.

8. Jaakkola P, Mole DR, Tian YM, et al. Targeting of HIF-alpha to the von Hippel-Lindau ubiquitylation complex by O2-regulated prolyl hydroxylation. Science. 2001;292:468-472.

9. Shuin T, Kondo K, Torigoe S, et al. Frequent somatic mutations and loss of heterozygosity of the von Hippel-Lindau tumor suppressor gene in primary human renal cell carcinomas. Cancer Res. 1994;54:2852-2855.

10. Kondo K, Yao M, Yoshida M, et al. Comprehensive mutational analysis of the VHL gene in sporadic renal cell carcinoma: relationship to clinicopathological parameters. Genes Chromosomes Cancer. 2002;34:58-68.

11. Gnarra JR, Tory K, Weng Y, et al. Mutations of the VHL tumour suppressor gene in renal carcinoma. Nat Genet. 1994;7:85-90.

12. Clifford SC, Prowse AH, Affara NA, Buys CH, Maher ER. Inactivation of the von Hippel-Lindau (VHL) tumour suppressor gene and allelic losses at chromosome arm 3p in primary renal cell carcinoma: evidence for a VHL-independent pathway in clear cell renal tumourigenesis. Genes Chromosomes Cancer. 1998;22:200-209.

13. Michaelson IC. The mode of development of the vascular system of the retina, with some observations on its significance for certain retinal diseases. Trans Ophthalmol Soc U K. 1948;68:137-180.

14. Leung DW, Cachianes G, Kuang WJ, Goeddel DV, Ferrara N. Vascular endothelial growth factor is a secreted angiogenic mitogen. Science. 1989;246:1306-1309.

15. Ferrara N, Henzel WJ. Pituitary follicular cells secrete a novel heparinbinding growth factor specific for vascular endothelial cells. Biochem Biophys Res Commun. 1989;161:851-858.

16. Vincenti V, Cassano C, Rocchi M, Persico G. Assignment of the vascular endothelial growth factor gene to human chromosome 6p21.3. Circulation. 1996;93:1493-1495.

17. Tischer E, Mitchell R, Hartman T, et al. The human gene for vascular endothelial growth factor. Multiple protein forms are encoded through alternative exon splicing. J Biol Chem. 1991;266:11947-11954.

18. Ferrara N, Davis-Smyth T. The biology of vascular endothelial growth factor. Endocr Rev. 1997;18:4-25.

19. Ruhrberg C, Gerhardt H, Golding M, et al. Spatially restricted patterning cues provided by heparin-binding VEGF-A control blood vessel branching morphogenesis. Genes Dev. 2002;16:2684-2698.

20. Carmeliet P, NgYS, Nuyens D, et al. Impaired myocardial angiogenesis and ischemic cardiomyopathy in mice lacking the vascular endothelial growth factor isoforms VEGF164 and VEGF188. Nat Med. 1999;5:495-502.
21. Fukumura D, Xavier R, Sugiura T, et al. Tumor induction of VEGF promoter activity in stromal cells. Cell. 1998;94:715-725.

22. Dames SA, Martinez-Yamout M, De Guzman RN, Dyson HJ, Wright PE. Structural basis for HIF-1 alpha/CBP recognition in the cellular hypoxic response. Proc Natl Acad Sci U S A. 2002;99:5271-5276.

23. Kibel A, Iliopoulos O, DeCaprio JA, Kaelin W. Binding of the von Hippel-Lindau tumor suppressor protein to Elongin B and C. Science. 1995;269:1444-1446.

24. Poltorak Z, Cohen T, Sivan R, et al. VEGF145, a secreted vascular endothelial growth factor isoform that binds to extracellular matrix. J Biol Chem. 1997;272:151-7158.

25. Roberts WG, Palade GE. Increased microvascular permeability and endothelial fenestration induced by vascular endothelial growth factor. J Cell Sci. 1995;108:2369-2379.

26. Bates DO, Lodwick D, Williams B. Vascular endothelial growth factor and microvascular permeability. Microcirculation. 1999;6:83-96.

27. Presta LG, Chen H, O'Connor SJ, et al. Humanization of an antivascular endothelial growth factor monoclonal antibody for the therapy of solid tumors and other disorders. Cancer Res. 1997;57:4593-4599.

28. Wang Y, Fei D, Vanderlaan M, Song A. Biological activity of bevacizumab, a humanized anti-VEGF antibody in vitro. Angiogenesis. 2004; 7:335-345

29. Gerber HP, Ferrara N. Pharmacology and pharmacodynamics of bevacizumab as monotherapy or in combination with cytotoxic therapy in preclinical studies. Cancer Res. 2005;65:671-680.

30. Rowe DH, Huang J, Kayton ML, et al. Anti-VEGF antibody suppresses primary tumor growth and metastasis in an experimental model of Wilms' tumor. J Pediatr Surg. 2000;35:30-33.

31. Gordon MS, Margolin K, Talpaz M, et al. Phase I safety and pharmacokinetic study of recombinant human anti-vascular endothelial growth factor in patients with advanced cancer. J Clin Oncol. 2001;19:843-850.

32. Margolin K, Gordon MS, Holmgren E, et al. Phase Ib trial of intravenous recombinant humanized monoclonal antibody to vascular endothelial growth factor in combination with chemotherapy in patients with advanced cancer: pharmacologic and long-term safety data. $J$ Clin Oncol. 2001;19:851-856.

33. Yang JC, Haworth L, Sherry RM, et al. A randomized trial of bevacizumab, an anti-vascular endothelial growth factor antibody, for metastatic renal cancer. $N$ Engl J Med. 2003;349:427-434.

34. Elaraj D, White DE, Steinberg SM, Hayworth L, Rosenberg SA, Yang JC. A pilot study of antiaglogenic therapy with bevacizumab and thalidomide in patients with metastatic renal cell carcinoma. J Immunotherapy. 2004;27:259-264.

35. Yuan F, Chen Y, Dellian M, Safabakhsh N, Ferrara N, Jain RK. Timedependent vascular regression and permeability changes in established human tumor xenografts induced by an anti-vascular endothelial growth factor/vascular permeability factor antibody. Proc Natl Acad Sci U SA. 1996;93:14765-14770.

36. Yang JC. Bevacizumab for patients with metastatic renal cancer: an update. Clin Cancer Res. 2004;10:6367S-6370S.

37. Viloria-Petit A, Crombet T, Jothy S, et al. Acquired resistance to the antitumor effect of epidermal growth factor receptor-blocking antibodies in vivo: a role for altered tumor angiogenesis. Cancer Res. 2001;61:5090-5101.

38. Knebelmann B, Ananth S, Cohen HT, Sukhatme VP. Transforming growth factor alpha is a target for the von Hippel-Lindau tumor suppressor. Cancer Res. 1998;58:226-231.

39. Hainsworth JD, Sosman JA, Spigel DR, et al. Treatment of metastatic renal cell carcinoma with a combination of bevacizumab and erlotinib. J Clin Oncol. 2005;23:7889-7896.

40. Hainsworth JD, Spigel DR, Sosman JA, et al. Treatment of advanced renal cell carcinoma with the combination bevacizumab/erlotinib/ imatinib: a phase I/II trial. Clin Genitourin Cancer. 2007;5:427-432.

41. Rowinsky EK, Schwartz GH, Gollob JA, et al. Safety, pharmacokinetics, and activity oFABX-EGF, a Fully human anti-epidermal growth Factor receptor monoclonal antibody in patients with metastatic renal cell cancer. J Clin Oncol. 2004;22:3003-3015. 
42. Bukowski RM, Kabbinavar FF, Figlin RA, et al. Randomized phase II study of erlotinib combined with bevacizumab compared with bevacizumab alone in metastatic renal cell cancer. J Clin Oncol. 2007;25: 4536-4541.

43. Motzer RJ, Bacik J, Murphy BA, et al. Interferon-alfa as a comparative treatment for clinical trials of new therapies against advanced renal cell carcinoma. J Clin Oncol. 2002;20:289-296.

44. Rini BI, Halabi Rosenberg SJ, et al. Bevacizumab plus interferon-alpha versus interferon-alpha monotherapy in patients with metastatic renal cell carcinoma: Results of overall survival for CALGB 90206. J Clin Oncol. 2009;27:18s(suppl):abstr LBA5019.

45. Escudier BJ, Bellmunt J, Negrier S, et al. Final results of the phase III, randomized, double-blind AVOREN trial of first-line bevacizumab $(\mathrm{BEV})+$ interferon- $\alpha 2 \mathrm{a}$ (IFN) in metastatic renal cell carcinoma (mRCC). J Clin Oncol. 2009;27:15s(suppl):abstr 5020.

46. Ko JS, Zea AH, Rini BI, et al. Sunitinib mediates reversal of myeloidderived suppressor cell accumulation in renal cell carcinoma patients. Clin Cancer Res. 2009;15:2148-2457.

47. Gabrilovich DI, Ishida T, Nadaf S, et al. Antibodies to vascular endothelial growth factor enhance the efficacy of cancer immunotherapy by improving endogenous dendritic cell function. Clin Cancer Res. 1999;5:2963-2970.

48. Tamir A, Jordan WJ, Ritter M, et al. Interferon-alpha2a is sufficient for promoting dendritic cell immunogenicity. Clin Exp Immunol. 2005; $142: 471-480$.

49. Dinney CP, Bielenberg DR, Perrotte P, et al. Inhibition of basic fibroblast growth factor expression, angiogenesis, and growth of human bladder carcinoma in mice by systemic interferon-B administration. Cancer Res. 1998;58:808-814.

50. Melichar B, Koralewski P, Ravaud A, et al. First-line bevacizumab combined with reduced dose interferon-a2a is active in patients with metastatic renal cell carcinoma. Ann Oncol. 2008;19:1470-1476.

51. Escudier B, Eisen T, Stadler WM, et al. Sorafenib for treatment of renal cell carcinoma: final efficacy and safety results of the phase III Treatment Approaches in Renal Cancer Global Evaluation Trial. J Clin Oncol. 2009;27:1-9.

52. Motzer RJ, Hutson TE, Tomczak P, et al. Overall Survival and Updated Results for Sunitinib Compared With Interferon Alfa in Patients With Metastatic Renal Cell Carcinoma. J Clin Oncol. 2009;27: 3584-3590.

53. Coon JS, Liu Z, Hoyle M, et al. Sunitinib and bevacizumab for first-line treatment of metastatic renal cell carcinoma: a systematic review and indirect comparison of clinical effectiveness. Br J Cancer. 2009; 101:238-243.

54. Benedict A, Charbonneau C, Hidi J, Kim ST, Negrier S. Economic evaluation of sunitinib, sorafenib, bevacizumab/interferon-alfa or temsirolimus in first-line treatment of metastatic renal cell carcinoma - a indirect comparison. J Clin Oncol. 2008;26(May 20 suppl):abstr 5048.

55. Mickisch G, Gore M, Escudier B, Procopio G, Walzer S, Nuijten M. Costs of managing adverse events in the treatment of first-line metastatic renal cell carcinoma: bevacizumab in combination with interferon-alpha2a compared with sunitinib. Br J Cancer. 2008. (Epub Nov 17, 2009).

56. National Institute for Clinical Excellence (NICE) Technology Appraisal Guidance 169: Sunitinib for the first-line treatment of advanced and/or metastatic renal cell carcinoma; issued March 2009. http//www.nice. org.uk/guidance/TA169.

Cancer Management and Research

\section{Publish your work in this journal}

Cancer Management and Research is an international, peer-reviewed open access journal focusing on cancer research and the optimal use of preventative and integrated treatment interventions to achieve improved outcomes, enhanced survival and quality of life for the cancer patient. The journal welcomes original research, clinical \& epidemiological

Submit your manuscript here: http://www.dovepress.com/cancer-management-and-research-journal
57. Ernstoff MS, Regan MM, McDermott DF, et al. First-line treatment with bevacizumab (B) and high dose (HD) bolus aldesleukin (IL-2) in metastatic renal cell carcinoma (mRCC) patients (Pts). J Clin Oncol. 2007; ASCO Annual Meeting Proceedings Part 1. Vol 25, No 18S:abstr 15524.

58. van der Vliet HJ, Koon HB, et al. Effects of the administration of high-dose interleukin-2 on immunoregulatory cell subsets in patients with advanced melanoma and renal cell cancer. Clin Cancer Res. 2007;13:2100-2108.

59. Garcia JA, Rini BI, Mekhail T, et al. A phase II trial of low-dose interleukin-2 (IL-2) and bevacizumab in patients with metastatic renal cell carcinoma (mRCC). J Clin Oncol. 2007; ASCO Annual Meeting Proceedings Part I. Vol 25, No. 18S(June 20 Suppl):abstr 5103.

60. DePrimo SE, Bello C. Surrogate biomarkers in evaluating response to anti-angiogenic agents: focus on sunitinib. Ann Oncol. 2007;18 Suppl 10: $11-19$.

61. Feldman D, Baum M, Ginsberg M, et al. Phase I trial of bevacizumab plus escalated doses of sunitinib in patients with metastatic renal cell carcinoma. J Clin Oncol. 2009;27:1432-1439.

62. Rini BI, Garcia JA, Cooney MM, et al. A phase I study of sunitinib plus bevacizumab in advanced solid tumors. Clin Cancer Res. 2009;15: 6277-6283.

63. Azad NS, Posadas EM, Kwitkowski VE, et al. Combination targeted therapy with sorafenib and bevacizumab results in enhanced toxicity and antitumor activity. J Clin Oncol. 2008;26:3709-3714.

64. Sosman JA, Flaherty KT, Atkins MB, et al. Updated results of phase I trial of sorafenib (S) and bevacizumab (B) in patients with metastatic renal cell cancer (mRCC). J Clin Oncol. 2008;26(May 20 suppl): Abstract 5011.

65. Whorf RC, Hainsworth JD, Spigel DR, et al. Phase II study of bevacizumab and everolimus (RAD001) in the treatment of advanced renal cell carcinoma (RCC). J Clin Oncol. 2008;26(May 20 suppl):abstr 5010.

66. Ayral-kaloustian S, Lucas GJ, Zask GC, et al. Hybrid inhibitors of phoisphatiylinositol 3-kinase (PI3K) and the mammalian target of rapamycin (mTOR): design, synthesis, and superior antitumor activity of novel wortmannin-rapamycin conjugates. J Med Chem. 2009. [Epub ahead of print $23 \mathrm{Nov}$.

67. Merchan JR, Liu G, Fitch T, et al. Phase I/II trial of CCI-779 and bevacizumab in stage IV renal cell carcinoma: phase I safety and activity results. J Clin Oncol. 2007;25(18S):abstr 5034.

68. Bevacizumab, sorafenib, and temsirolimus in treating patients with metastatic kidney cancer. Clinical Trials.gov, NCT00378703.

69. Combination of Temsirolimus and Bevacizumab in Patient With Metastatic Renal Cell Carcinoma (TORAVA). ClinicalTrials.gov, NCT 00619268

70. Jonasch E, Wood CG, Matin SF, et al. Phase II presurgical feasibility study of bevacizumab in untreated patients with metastatic renal cell carcinoma. J Clin Oncol. 2009;27:4076-4081.

71. Kabbinavar FF, HambletonJ, Mass RD, et al. Combined analysis of efficacy: The addition of bevacizumab to fluorouracil/leucovorin improves survival for patients with metastatic colorectal cancer. J Clin Oncol. 2005;23:3706-3712.

72. Rugo HS. Bevacizumab in the treatment of breast cancer: Rationale and current data. Oncologist. 2004;9(Suppl 1):43-49.

73. Johnson DH, Fehrenbacher L, Novotny WF, et al. Randomized phase II trial comparing bevacizumab plus carboplatin and paclitaxel with carboplatin and paclitaxel alone in previously untreated locally advanced or metastatic non-small-cell lung cancer. J Clin Oncol. 2004;22: 2184-2191.

\section{Dovepress}

studies, reviews \& evaluations, guidelines, expert opinion \& commentary, case reports \& extended reports. The manuscript management system is completely online and includes a very quick and fair peerreview system, which is all easy to use. Visit http://www.dovepress.com/ testimonials.php to read real quotes from published authors. 